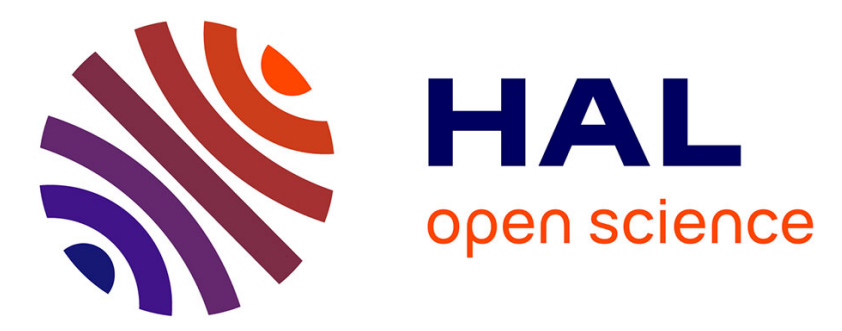

\title{
Authoritarian attitudes are associated with higher autonomic reactivity to stress and lower recovery
}

Johan Lepage, Laurent Bègue, Oulmann Zerhouni, Michael Dambrun, Kevin

Vezirian, Théo Besson, Solenne Bonneterre, Martial Mermillod

\section{- To cite this version:}

Johan Lepage, Laurent Bègue, Oulmann Zerhouni, Michael Dambrun, Kevin Vezirian, et al.. Authoritarian attitudes are associated with higher autonomic reactivity to stress and lower recovery. Emotion, 2022, 22 (3), pp.526-544. 10.1037/emo0000775 . hal-02978765

\section{HAL Id: hal-02978765 \\ https://hal.science/hal-02978765}

Submitted on 17 Nov 2020

HAL is a multi-disciplinary open access archive for the deposit and dissemination of scientific research documents, whether they are published or not. The documents may come from teaching and research institutions in France or abroad, or from public or private research centers.
L'archive ouverte pluridisciplinaire HAL, est destinée au dépôt et à la diffusion de documents scientifiques de niveau recherche, publiés ou non, émanant des établissements d'enseignement et de recherche français ou étrangers, des laboratoires publics ou privés. 
Authoritarian attitudes are associated with higher autonomic reactivity to stress and lower recovery

Johan Lepage $^{1}$, Laurent Bègue ${ }^{1}$, Oulmann Zerhouni ${ }^{2}$, Michael Dambrun ${ }^{3}$, Kevin Vezirian ${ }^{1}$, Théo Besson $^{2}$, Solenne Bonneterre ${ }^{2}, \&$ Martial Mermillod ${ }^{4,5}$

${ }^{1}$ Université Grenoble Alpes, Laboratoire Interuniversitaire de Psychologie

${ }^{2}$ Université Paris Nanterre, Laboratoire Parisien de Psychologie Sociale

${ }^{3}$ Université Clermont Auvergne, Laboratoire de Psychologie Sociale et Cognitive

${ }^{4}$ Université Grenoble Alpes, Laboratoire de Psychologie et NeuroCognition

${ }^{5}$ Institut Universitaire de France

\section{Corresponding author}

Johan Lepage, PhD: Laboratoire Interuniversitaire de Psychologie, UFR SHS, 1251 avenue Centrale, BP 47, 38040 Grenoble Cedex 9, France; E-mail: johan.lepage@gmail.com , Phone: (+33 4) 7682 58 92, Fax: (+33 4) 76825665

\section{Contact information}

Laurent Bègue, PhD: Laboratoire Interuniversitaire de Psychologie, UFR SHS, 1251 avenue Centrale, BP 47, 38040 Grenoble Cedex 9, France; E-mail: laurent.begue@msh-alpes.fr, Phone: (+33

4) 768273 00, Fax: (+33 4) 76827301 
Oulmann Zerhouni, PhD: Laboratoire Parisien de Psychologie Sociale, Département de Psychologie, 200 avenue de la République, 92000 Nanterre, France; E-mail: zerhounioulmann@gmail.com, Phone: (+33 4) 768258 92, Fax: (33 4) 76825665

Michael Dambrun, PhD: Laboratoire de Psychologie Sociale et Cognitive, UFR Psychologie, 34 avenue Carnot, 63037 Clermont-Ferrand Cedex, France; E-mail: michael.dambrun@uca.fr, Phone: (+33 4) 734064 81, Fax: (+33 4) 73406482

Kevin Vezirian, PhD student: Laboratoire Interuniversitaire de Psychologie, UFR SHS, 1251 avenue Centrale, BP 47, 38040 Grenoble Cedex 9, France; E-mail: kevin.vezirian@gmail.com, Phone: (+33 4) 768273 00, Fax: (+33 4) 76827301

Théo Besson, PhD student: Laboratoire Parisien de Psychologie Sociale, Département de Psychologie, 200 avenue de la République, 92000 Nanterre, France; E-mail: theo.besson@gmail.com, Phone: (+33 4) 768258 92, Fax: (33 4) 76825665

Solenne Bonneterre, PhD student: Laboratoire Parisien de Psychologie Sociale, Département de Psychologie, 200 avenue de la République, 92000 Nanterre, France; E-mail: solenne.bonneterre@gmail.com, Phone: (+33 4) 768258 92, Fax: (33 4) 76825665

Martial Mermillod, PhD: Laboratoire de Psychologie et NeuroCognition, UFR SHS, 1251 avenue Centrale, BP 47, 38040 Grenoble Cedex 9, France; E-mail: martial.mermillod@univ-grenoblealpes.fr, Phone: (+33 4) 768258 93, Fax: (+33 4) 76827834 


\begin{abstract}
Right-wing authoritarianism (RWA) and social dominance orientation (SDO) both predict generalized prejudice, dehumanization, intergroup discrimination, oppression, and violence, right-wing political party preference and generally punitive attitudes. Authoritarian attitudes have been theorized to involve maladaptive emotional, cognitive and social self-regulation. However, there is no study of authoritarianism using the functioning of the parasympathetic nervous system (PNS) as a physiological index of self-regulation, thus leaving it unclear whether regulation is "impaired" with authoritarian attitudes per se. PNS functioning is commonly assessed by examining tonic and phasic heart rate variability (HRV). These two components are recognized to be important in terms of adaptation to stress. Decreased HRV has been associated with hypoactive prefrontal regulation, hyperactive subcortical structures, maladaptive self-regulation, hyper-vigilance, decreased prosocial tendencies, defensiveness, impulsive behaviors and aggression. Previous research suggests that self-regulatory failure may favor hostile attitudes prejudicial intergroup behaviors. In a first study we found that high RWA was associated with lower tonic HRV at rest. In a second study, stress-induced autonomic reactivity and post-stress autonomic recovery were examined as potential pathways linking authoritarian attitudes to self-regulation. We found that high RWA and high SDO were associated (i) with lower tonic HRV during stress, (ii) with greater autonomic reactivity during stress, (iii) lower autonomic recovery. Overall, our results suggest that autonomic dysregulation during and following stress is a plausible physiological pathway connecting RWA and SDO to self-regulation. Implications of such results for research on political attitudes are discussed.
\end{abstract}

\title{
Keyword
}

Right-wing authoritarianism; social dominance orientation; cardiac vagal control; threat; stress 


\section{Introduction}

Early social psychological research found that some people tend to be generally prejudiced and others generally tolerant. Moreover, individuals high in prejudice are also ethnocentric, nationalistic, socially-conservative and politically right-wing. In contrast, low prejudice individuals tend to be tolerant and liberal. Subsequent research have shown that individuals' tendencies to be generally prejudiced or tolerant are powerfully (and relatively independently) predicted by two important individual difference dimensions, right-wing authoritarianism (RWA) and social dominance orientation (SDO), with no other psychological factors adding notably to prediction ${ }^{1}$. Across human cultures, these two individual difference orientations are relatively stable over the lifecourse (e.g. Altemeyer, 1996; Ludeke \& Krueger, 2013).

A great deal of research has been devoted to explain the origins and manifestations of authoritarianism. A large number of studies have consistently shown that perceived threat produces a shift in authoritarianism. However, individuals vary markedly in their attitudinal responses to threats and the reasons for individual variability remain unknown (Oxley et al., 2008). As stated by the authors, "one possibility is that people vary in general physiology and that certain of these variations encourage the adoption of particular political attitudes." The present research aimed to advance our understanding of the ways in which physiology may influence the development and manifestations of authoritarian attitudes. The polyvagal theory (Porges, 2007) and the neurovisceral integration model (Thayer \& Lane, 2000; Thayer, Hansen, Saus-Rose, \& Johnsen, 2009) both causally relate cardiac vagal control (CVC) with self-regulation processes and social functioning. Based on studies suggesting that authoritarian attitudes are associated with (or result from) maladaptive emotional, cognitive

\footnotetext{
${ }^{1}$ Studies have shown that other constructs contribute to variance in prejudice (e.g., McFarland, 2010) but the observed correlations were weak and not consistently replicated (see Duckitt \& Sibley, 2017).
} 
and social self-regulation, the present research aimed to explore the association between RWA, SDO and CVC.

\section{Motivationally based social-ideological attitudes}

The RWA scale (Altemeyer, 1981, 1988, 1998) captures the covariation of three dimensions:

(i) authoritarian submission (a submissive, uncritical attitude toward authorities), (ii) authoritarian aggression (tendency to condemn, reject, and punish people who violate conventional values), and (iii) conventionalism (rigid adherence to traditional moral and religious norms). RWA is highly correlated with measures of social and cultural conservatism (e.g., Duckitt, 2001). The SDO scale measures "a general attitudinal orientation toward intergroup relations, reflecting whether one prefers such relations to be equal, versus hierarchical" (Pratto, Sidanius, Stallworth \& Malle, 1994). SDO is highly correlated with measures of anti-egalitarianism and economic conservatism (for a review see Duckitt \& Sibley, 2009). RWA and SDO both predict dehumanization and violent behaviors such as aggression against dissident groups, ethnic persecution of immigrants and torture-like abuse (e.g., Henry, Sidanius, Levin, \& Pratto, 2005; Kteily, Bruneau, Waytz, \& Cotterill, 2015; Larsson, Björklund, \& Bäckström, 2012; Thomsen, Green, \& Sidanius, 2008).

RWA has been linked to stable characteristics of individuals that could cause them to be generally more or less prejudiced against out-groups: (i) low openness to experience and high conscientiousness (e.g., Duckitt, 2001), (ii) need for order, closure and structure (e.g., Cornelis \& Van Hiel, 2006; Kossowska \& Van Hiel, 2003; Van Hiel, Pandelaere, \& Duriez, 2004). Behavioral genetic research found evidence that genetic influences contribute significantly to individual differences in RWA (i.e., genetic influences primarily explained twin pairs' resemblance in RWA; e.g., Ludeke \& Krueger, 2013). SDO has been linked to antisocial personality traits such as Psychopathy, Machiavellianism, reduced concern for the others' well-being, and low agreeableness (e.g., Duckitt \& Sibley, 2010; Hodson, Hogg, \& 
MacInnis, 2009; Sidanius \& Pratto, 1999). However, SDO seems to be more context-sensitive than RWA (see Kandler et al., 2016).

The dual process motivational model of ideology and prejudice (DPM; Duckitt \& Sibley, 2010, 2017) encompasses both psychological and situational factors to explain systematic individual differences in generalized prejudice. This model "proposes that the motivationally based values expressed in RWA and SDO are made chronically salient for individuals by both their personalities and their social worldview beliefs (formed by exposure to and socialization in particular social environments)" (Duckitt \& Sibley, 2017). High RWA represents the motivational goals of collective security, control, stability, and order, which are made chronically salient by the belief that the social world is inherently dangerous and threatening. High SDO represents the motivational goals of power, dominance, and superiority over others, chronically salient because of a view of the world as a ruthlessly competitive jungle in which the strong win and the weak lose. The DPM states that these two basic human motivational goals would be largely activated by threat, inequality and competition.

\section{Authoritarian attitudes and threats}

Research has provided evidence that particular threat cues activate dual motivational goals expressed in RWA and SDO, and that authoritarian individuals are particularly likely to overreact to threat cues. In the case of RWA, studies have shown a strong influence of social threats (threats to societal stability, order and cohesion) on levels of RWA: (i) perceived social threat increases RWA at both individual and societal levels, (ii) experimental manipulation of social threat influence RWA scores, (iii) high RWA individuals are more reactive to social threat, more motivated to control social threat, and more hostile to out-groups that seem to threaten collective security (for a review see Duckitt \& Sibley, 2017). In the case of SDO, studies found an influence of competitive threats, where the social context involves competitiveness with out-groups: (i) individuals higher in social status are higher in SDO, (ii) 
individuals that identify with high status membership groups have higher SDO (e.g., Morrison, Fast, \& Ybarra, 2009; Morrison \& Ybarra, 2008). Research has also shown that high SDO individuals (i) react to competitive threats with increased effort and readiness to break rules to win at all costs (Cozzolino \& Snyder, 2008), (ii) are more competitive toward lower-status out-groups (e.g., Danso \& Esses, 2001), (iii) are more hostile to out-groups that are seen as challenging relative group dominance (e.g., Eibach \& Keegan, 2006).

As mentioned above, people vary greatly in their attitudinal responses to threats and the reasons for this variability remain unknown. One possibility is that individual variations in physiology encourage the adoption of particular political attitudes (Oxley et al., 2008).

\section{Implicit processes and biological mechanisms}

\section{Authoritarian attitudes}

With regard to implicit, subthreshold tendencies, RWA has been associated with automatic recognition of negative words suggesting threats to social order and group cohesion (Feldman, Lavine, Lodge \& Verhulst, 2010). Very few studies have investigated the biological mechanisms of authoritarian attitudes. An electroencephalographic study examined the association between RWA and conflict monitoring, an important aspect of cognitive selfregulation (Weissflog et al., 2010). Using a "Go/No-Go task", the authors found that RWA was associated with lower conflict-related neural activity (i.e., lower error-related negativity and No-Go N2 amplitudes). An fMRI study investigated the association between SDO and neural responses to the pain of others (Chiao, Mathur, Harada, \& Lipke, 2009). The authors found an inverse relation between SDO scores and neural responses when perceiving pain in others within fronto-insular regions critical to the ability to share and feel concern for the other's suffering (i.e., anterior cingulate cortex and anterior insula). 
Other studies found that conservatives are more prone to perceive "emotionally ambiguous" faces as expressing a threatening or a dominant emotion (Vigil, 2010), and to perceive negative images more negatively (Hibbing, Smith, \& Alford, 2014). Conservatives have also been found "to be quicker to focus on the negative, to spend longer looking at the negative, and to be more distracted by the negative" (Hibbing et al., 2014). Using a "Go/No-Go task", Amodio, Jost, Master and Yee (2007) found that conservatism was associated with lower behavioral accuracy on No-Go trials and lower conflict-related neural activity when response inhibition is required. Oxley et al. (2008) investigated the relation between political beliefs and sympathetic response to threat. The authors found that conservatism was associated with larger skin conductance responses to threatening images (heightened skin conductance response reflects sympathetic activation), and stronger defensive startle reflex in response to unexpected auditory prompts. Using structural MRI, Kanai et al. (2011) found that conservatism was associated with lower anterior cingulate cortex volume (a cortical structure which play a critical role in cognitive flexibility) and larger right amygdala volume (a subcortical structure which play a critical role in fear-related behaviors, such as the evaluation of actual or potential threats). Researchers have also turned to molecular genetics approaches. For example, Hatemi et al. (2011) found that genetic polymorphisms related to both cognitive flexibility and threat sensitivity predicted scores on a general attitudinal measure of liberalism-conservatism.

\section{Theoretical models of ideology}

The uncertainty-threat model of ideology (e.g., Jost, Glaser, Kruglanski, \& Sulloway, 2003) posits that political conservatism is associated with the psychological needs to manage uncertainty and threat. Hibbing et al. (2014) proposed that individual differences in negativity bias may underlie variations in ideology. Tritt, Peterson and Inzlicht (2013) argued that emotional arousal, in general, and not negative valence, specifically, may underlie 
conservatism. In this perspective, the effect of negative emotion on the experience and expression of conservatism is due to engaging intensely arousing states. Amodio et al. (2007) stated that political orientation "reflects individual differences in the functioning of a general mechanism related to cognitive control and self-regulation".

These theoretical propositions are comprehensive and thought-provoking but no studies of ideology have used the functioning of the parasympathetic nervous system (PNS) as a physiological index of self-regulation, thus leaving it unclear whether regulation is "impaired" in authoritarian attitudes per se. As we have just summarized, a good deal of research has provided evidence that authoritarian attitudes are associated with cognitive rigidity, hyper-vigilance to threat-related stimuli, intolerance, disruptive and violent behaviors. These findings suggest that RWA and SDO may result from maladaptive emotional and cognitive self-regulation, and inadequate adaptability. This general assumption could be tested using CVC, a physiological indicator of self-regulation.

\section{Cardiac vagal tone as an index of self-regulation processes}

The autonomic nervous system (ANS) is subdivided into an excitatory sympathetic nervous system (SNS) and an inhibitory parasympathetic nervous system. When an individual is threatened, the activity of the SNS becomes dominant, triggering a suite of physiological responses to aid in adapting to the challenge (e.g., increased heart rate). In a safe context, the PNS is dominant and maintains a lower degree of physiological arousal (e.g., decreased heart rate). CVC represents the PNS contribution to cardiac regulation. The polyvagal theory (Porges, 2007) causally relates CVC with emotion-related self-regulation and prosocial tendencies.

\section{Polyvagal theory}


The polyvagal theory articulates three neural circuits regulating the heart: (i) the "social engagement system" is dependent upon the functions of the myelinated vagus "which serves to foster calm behavioral states by inhibiting the sympathetic influences to the heart" (Porges, 2007); (ii) the "fight-or-flight system" is dependent on the functioning of the SNS; (iii) the "immobilization system" is dependent on the unmyelinated vagus. In safe contexts, there is an increased influence of the myelinated vagus on the cardiac pacemaker that slows the heart and inhibits the fight/flight mechanisms of the SNS. The two more primitive neural circuits serve to ensure survival in life-threatening contexts through defensive strategies (i.e., fight-flight and death-feigning behaviors). Under resting conditions, the myelinated vagus acts as a "brake", firing a rapid and continuous signal that slows the heart. The polyvagal theory also states that a neural process termed "neuroception" continuously evaluates risk and modulates vagal activity via higher brain structures. An invalid neuroception of danger is believed to contribute to maladaptive physiological reactivity and the expression of the defensive behaviors associated with negative emotional states (e.g., fear, anxiety; Porges, 2007). The strength of the cardiac vagal tone is commonly assessed by examining heart rate variability (HRV) at rest. Following the polyvagal perspective, higher resting HRV should be related to higher self-regulatory control and prosocial tendancies. Consistently, studies found that higher resting HRV predicted greater regulatory control, decreased negative emotional arousal in response to stressors, engagement coping, sympathy, compassion and helping behavior (e.g., Fabes \& Eisenberg, 1997; Geisler, Kubiak, Siewert, \& Weber, 2013; Stellar, Cohen, Oveis, \& Keltner, 2015). By contrast, lower resting HRV has been related to personal distress, psychosocial stress, social anxiety and defensiveness (e.g., Movius \& Allen, 2005; Porges, 1992; Thayer \& Lane, 2007). More generally, a "host of findings suggest that human subjects with greater vagal influence may be dispositionally more open to experience and better able to self-regulate" (Movius \& Allen, 2005). 


\section{Neurovisceral integration model}

The neurovisceral integration model (Thayer \& Lane, 2000; Thayer et al., 2009) states that the neural networks implicated in cognitive and emotion self-regulation (e.g., ventromedial prefrontal cortices, anterior cingulate, insula, amygdala) are also involved in the control of cardiac activity. In safe contexts, the prefrontal cortex is believed to exert an inhibitory control over sympatho-excitatory subcortical circuits (e.g., Thayer et al., 2009). In threatening contexts, the prefrontal inhibitory regulation diminishes and sympatho-excitatory subcortical circuits produce default threat responses (e.g., Park, Vasey, Van Bavel, \& Thayer, 2014). Consistently, brain imaging studies find that reduced prefrontal activity is responsible for hyperactive subcortical activity, prolonged activation of defensive behaviors and hypervigilance (e.g., Thayer et al., 2009; Park et al., 2014). Research also provides evidence that the functioning of prefrontal-subcortical inhibitory circuits is linked with the heart via the vagus nerve. For instance, studies found that lower HRV at rest is associated with hypoactive prefrontal regulation, hyperactive subcortical structures, maladaptive cognitive and emotion regulation, increased negativity bias (i.e., the tendency to prioritize negative information over positive) and decreased willingness to approach positive novel objects (see Thayer, Ahs, Fredrikson, Sollers, \& Wager, 2012). In this perspective, HRV at rest reflects inhibitory prefrontal processes and represents a useful index of threat perceptions and therefore of stress.

\section{Other theories linking HRV to self-regulation}

Five other theories causally relate HRV to self-regulation processes: the generalized unsafety theory of stress (Brosschot, Verkuil, \& Thayer, 2016, 2018), the vagal tank theory (Laborde, Mosley, \& Mertgen, 2018), the biological behavioral model (Grossman \& Taylor, 2007), the resonance frequency model (Lehrer, 2013), and the psychophysiological coherence model (McCraty \& Childre, 2010). 
According to the generalized unsafety theory of stress (GUTS), the default state of our human organism is a state of generalized unsafety in which the stress response "stays on". As long as safety is perceived, the default stress response is under tonic prefrontal inhibition (reflected by high resting HRV). Safety signals are social and learned during the life cycle. Safety learning can "go wrong" in many ways: inherited psychological vulnerability, early life stress, exposure to social contexts compromised in terms of perceived safety. Studies have shown that failure in recognizing safety is not restricted to stress-related disorders: having a low resting HRV seems sufficient for not recognizing safety. For example, low HRV has been associated with stronger startle responses to neutral stimuli (Ruiz-Padial, Sollers, Vila, \& Thayer, 2003), deficient safety learning (Pappens et al., 2014; Wendt, Neubert, Koening, Thayer, \& Hamm, 2015), and increased contextual fear conditioning (Melzig, Weike, Hamm, \& Thayer, 2009). Within the GUTS framework, low resting HRV is an index of the chronically disinhibited default stress response.

The vagal tank theory depicts vagal efferent activity to the heart as "an indicator of centralperipheral neural feedback and central nervous system-autonomous nervous system integration, justifying its role as a general summarizing self-regulation index" (Laborde et al., 2018). The biological behavioral model posits that HRV plays a primary role in energy regulation by synchronizing respiratory and cardiovascular processes. Within this framework, a higher resting HRV reflects "a functional energy reserve capacity from which the organism can draw during more active states" (Grossman \& Taylor, 2007). The resonance frequency model and the psychophysiological coherence model both state that higher vagal tone can be achieved through slow-paced breathing. McCraty and Childre (2010) postulate that slowpaced breathing coupled with positive emotions will produce a large range of positive personal, social and health outputs.

\section{Social cognition}


Only a few studies have examined the role of the ANS in social cognition. Being able to recognize subtle facial cues and to infer the likely mental states of the others is an important feature of social cognition (Quintana, Guastella, Outhred, Hickie, \& Kemp, 2012). The authors found evidence that increased resting HRV is a sensitive biomarker of one's ability to recognize emotions. This is consistent with reports of reduced cardiac vagal tone in psychiatric disorders characterized by social cognition impairments, including depression and anxiety (e.g., Kemp, Quintana, Felmingham, Matthews, \& Jelinek, 2012). Other studies suggest that down-regulation of the amygdala by the prefrontal cortex is required to regulate attitudes and to avoid prejudicial intergroup behavior (see Heatherton \& Wagner, 2011). Selfregulatory failure may favor stereotyping and the expression of defensive behaviors associated with negative emotional states. In line with this assumption, decreased cardiac vagal tone has been associated with (i) greater difficulties with emotional clarity, (ii) greater difficulties in controlling impulsive behaviors when experiencing negative emotions (Williams et al., 2015), and (iii) reactive aggression (i.e., visceral defensive response to perceived threat; Scarpa, Haden, \& Tanaka, 2010).

\section{Hypotheses}

Within the DPM, RWA is defined as a "threat-driven attitudinal expression of the values or motivational goals of collective security, control, stability, and order"; SDO is defined as a "competition-driven attitudinal expression of the values or motivational goals of power, dominance, and superiority" (Duckitt \& Sibley, 2017). As we just summarized, resting HRV reflects self-regulation processes and represents a reliable biomarker of threat perceptions and stress. There is also growing appreciation that the ANS plays an important role in social cognition. First, we hypothesized a negative relation between resting HRV and RWA. In a second step, we also hypothesized a negative relation between resting HRV and SDO. 
However, because the latter attitude is more context-sensitive, we expect it to have a less robust association with HRV at rest.

\section{Study 1}

\section{Material and method}

\section{Participants}

To our knowledge, none of the previous studies tested the association between HRV and authoritarian attitudes. Based on works highlighting a link between HRV at rest and personality variables (Movius \& Allen, 2005; Scarpa, Haden, \& Tanaka, 2010), we planned between 115 and 120 participants to take part in the study. 119 healthy adults ( 83 females, $\left.M_{\text {age }}=22.15 ; S D_{\text {age }}=2.76\right)$ volunteered for the experiment in exchange for course credit. They provided written informed consent before the participation. The study was reviewed and approved by the local human ethics committee (ethics committee notice number 2013-07-0423).

To be eligible, participants had to be aged between 18 and 50 years, with normal or correctedto-normal vision, as well as explicitly reporting an absence of psychiatric, neurological, cardiovascular, endocrine or immunological disorders and no treatment that could modulate brain activity (benzodiazepine, antidepressants, neuroleptics, lithium, etc. ; for a review of exclusion criterion see Laborde, Mosley, \& Thayer, 2017). Participants were told to refrain from smoking, caffeinated drinks (e.g., coffee, tea, energy drinks) and psychotropic substances (e.g. alcohol, cannabis, etc.) on the day of the experiment. They were also to avoid eating or drinking (except water) in the 2 hours preceding the experiment in order to limit the influence of digestion on autonomic functioning, but were to eat in the morning (more than 2 hours before the experiment) in order to avoid fasting states. Short term HRV measurement can be biased by the digestion of food since viscera are innervated by the autonomic nervous 
system (Heathers, 2014; Iorfino, Alvares, Guastella, \& Quintana, 2015; Quintana \& Heathers, 2014). Finally, they had to avoid water consumption 30 minutes before the experiment and were asked to empty their bladder before starting the experiment.

\section{Heart rate variability}

HRV measurements were taken with both time domain and frequency domain methods. In the time-domain, the most popular estimate of HRV is RMSSD (root mean square of successive R-R differences), which is calculated as the standard deviation of the beat-to-beat intervals, reflecting vagal tone (Laborde et al, 2017). A popular frequency-domain technique to estimate HRV involves decomposing heart period variance into different frequency bands using Fourier transformations. The high frequencies $(\mathrm{HF}, 0.15-0.4 \mathrm{~Hz})$ represent primarily vagal influence, and as such, parasympathetic activity (e.g., Montano, Porta, \& Malliani, 2001). The low frequencies (LF, 0.04-0.15 Hz) reflect a mix of sympathetic and vagal activity (see Negrao, Bipath, van der Westhuizen, \& Viljoen, 2011, for a summary). RMSSD and HF are positively correlated (e.g., Otzenberger et al., 1998). However, RMSSD is relatively free of respiratory influences, in contrast to HF (Hill \& Siebenbrock, 2009).

Resting HRV was recorded over 10 minutes. Three $\mathrm{Ag}-\mathrm{AgCl}$ electrodes were attached as follows: one electrode (Negative) in the right infraclavicular fossa (just below the rigid clavicle) and one electrode (Positive) on the left 4th or 5th rib mid-clavicular to axillary line, with the Ground on right 4th or 5th rib mid-clavicular to axillary line. ECG (sampling rate $1000 \mathrm{~Hz}$ ) was recorded using Single BIO Amp hardware in conjunction with PowerLab 16/32 hardware and LabChart 8 software (ADInstruments Ltd, NZ).

\section{Procedure}

The experiment took place in a quiet and dimmed room; with participants on a comfortable seat. Baseline was recorded during 10 minutes while sitting with knees at a $90^{\circ}$ angle, both 
feet flat on the floor, hands on thighs (palms facing upward) and eyes closed. Participants were asked stay seated without speaking or making any movements, to relax and to breathe spontaneously. The first 5 minutes allowed participants to shift into a quiet state and HRV baseline was assessed during the last 5 minutes (e.g., Ghuman, Campbell, \& White, 2009; Laborde et al., 2017; Quintana, Alvares, \& Heathers, 2016). When this step ended, participants completed an online survey (Inquisit Web). RWA was assessed using 10 items ( $\alpha$ $=.77)$ from Altemeyer's 20 -item (1988) RWA Scale $(1=$ totally disagree to $7=$ totally agree $)$. SDO was assessed using 10 items $(\alpha=.84)$ from the SDO Scale (Sidanius \& Pratto, 1999; $1=$ totally disagree to $7=$ totally agree $)$.

\section{Data analysis}

Prior to analysis, the signal was visually inspected and ectopic (abnormal) heart beats were removed using the LabChart Beat Classifier view. The HRV 2.0 Add-On for LabChart was used to calculate RMSSD (root mean square of successive R-R differences), HF (0.15-0.4 Hz; normalized units) and LF (0.04-0.15 Hz; normalized units). The HRV 2.0 Add-On module uses the Lomb Periodogram nonparametric method for spectral analysis which, unlike the Fast Fourier Transform method, can compute the spectral frequencies directly from the unevenly sampled tachogram.

When the research question is based on vagal tone it has been recommended to perform the analyses with one main variable indexing vagal tone for comprehension purposes (e.g., Laborde et al., 2017). Thus, our hypotheses were tested using multiple linear regression with RMSSD as predictor variable, controlling for sex, age, weight, height, alcohol, tobacco consumption, oral and subcutaneous contraception. However, correlations between time and frequency domain parameters were calculated to check their relation (RMSSD and HF should be positively associated; LF should be negatively associated with RMSSD and HF).

\section{Results}


Correlation results showed the expected patterns: parasympathetic parameters (RMSSD, HF) were positively associated with each other; LF was negatively associated with parasympathetic parameters (see Table 1). 
Table 1

Descriptive statistics and correlations between heart rate variability parameters and authoritarian attitudes

1

1 RWA

$2 \mathrm{SDO}$

3 RMSSD

$4 \mathrm{HF}$

$5 \mathrm{LF}$

$M(\mathrm{SD})$
2

.40

$-$

$-.15$

$-$

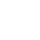

4

$-.27$

$-.27$

.43

$-.44$

$\begin{array}{ll}- & -.99\end{array}$

$2.98(.86)$

$2.24(.89)$

$43.48(24.47)$

$42.16(19.63)$

$57.85(20.01)$

Note. $\mathrm{RWA}=$ right-wing authoritarianism; $\mathrm{SDO}=$ social dominance orientation; $\mathrm{RMSSD}=$ root mean square of successive R-R differences; $\mathrm{HF}=$ high frequencies $(0.15-0.4 \mathrm{~Hz})$ expressed in normalized units; $\mathrm{LF}=$ low frequencies $(0.04-0.15 \mathrm{~Hz})$ expressed in normalized units. ${ }^{2}$

\footnotetext{
${ }^{2}$ As the total power of the spectral signal is heterogeneous from person to person, it has been recommended that HF and LF data should be presented as normalized values (e.g., Pagani et al., 1986).
} 
As predicted, a multiple linear regression showed that lower RMSSD at rest was associated with higher RWA scores. RMSSD at rest was a marginally significant predictor of SDO scores (see Table 2).

Table 2

Multiple linear regressions examining the associations between heart rate variability and authoritarian attitudes

$\begin{array}{lllccc}\text { Criterion variables } & \text { Predictor variables } & \beta & t & p & 95 \% \text { CI } \\ & & & & & \\ \text { RWA } & \text { RMSSD } & -.45 & -5.13 & .000 & {[-.02,-.01]} \\ \text { SDO } & \text { RMSSD } & -.17 & -1.77 & .07 & {[-.01, .001]}\end{array}$

Note. RWA = right-wing authoritarianism; $\mathrm{SDO}=$ social dominance orientation; RMSSD $=$ root mean square of successive R-R differences.

These regression analyses suggest that RWA and, to a lesser extent, SDO were associated with decreased resting HRV (see Figure 1). These findings support the general assumption that authoritarian attitudes are associated with (or result from) maladaptive self-regulation. 

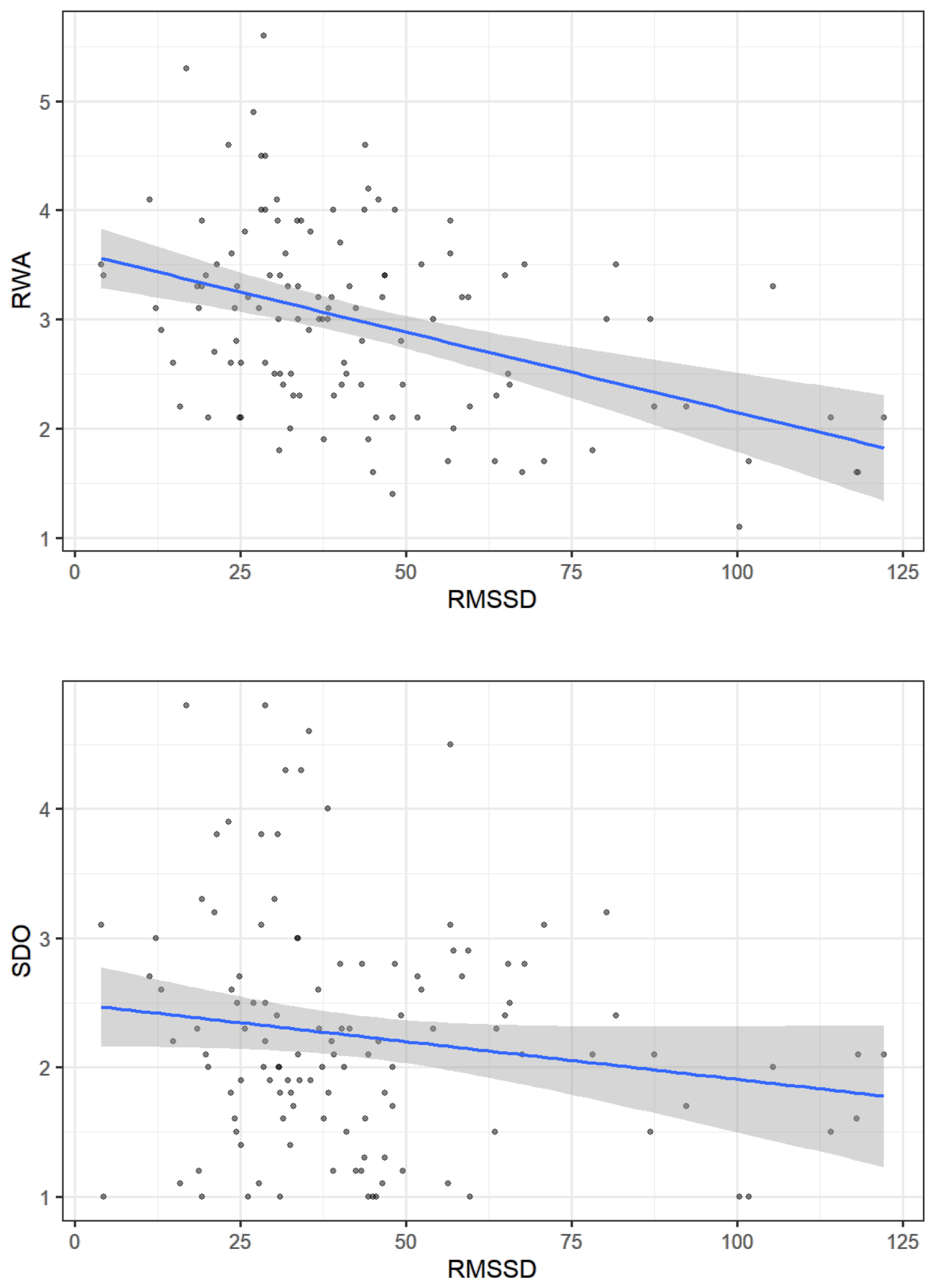

Figure 1. (A) Scatterplot of RMSSD (at rest) and right-wing authoritarianism (RWA), (B) scatterplot of RMSSD (at rest) and social dominance orientation (SDO). 


\section{Study 2}

The most popular estimate of HRV is RMSSD and we found that lower RMSSD was associated with higher RWA and SDO scores. The polyvagal theory and the neurovisceral integration model both lead to the conclusion that authoritarian attitudes may reflect individual differences in a predisposition to chronically perceive threat associated with dysregulated brain-peripheral integration (as indexed by low resting HRV). In other words, chronic difficulties in inhibiting the default response mode to threat, in down-regulating the sympatho-excitatory, cardio-acceleratory subcortical threat circuits, (i) may limit the ability to challenge invalid threat perception and to display prosocial tendencies, (ii) may promote authoritarian attitudes and aggressive behaviors toward outgroups that seem to threaten collective security or relative group dominance.

Resting HRV has been the focus of most research considering CVC, and represents the basis for the main prediction of psychophysiological theories involving HRV. However, both tonic HRV (the value at a specific time point measurement) and phasic HRV (the change of values between two time point measurements) are recognized to be important in terms of adaptation (e.g., Laborde, Mosley, \& Mertgen, 2018; Porges, 2007; Thayer et al., 2012). Research highlights that different change patterns (i.e., direction and magnitude) of HRV are adaptive or maladaptive for self-regulation depending on the situation. For instance, vagal withdrawal (decrease in HRV) may be seen as (i) adaptive when the individual is facing a physical stressor or a mental stressor that does not involve executive function (e.g., Rottenberg, Salomon, Gross, \& Gotlib, 2005; Messerotti Benvenuti, Mennella, Buodo, \& Palomba, 2015), (ii) maladaptive when the stressor faced by the individual requires executive functioning (e.g., Park et al., 2014). Vagal enhancement (increase in HRV) is seen as adaptive when selfregulation requires mental effort (vagal brake engagement to make resources available for the metabolic costs of an effort based on top-down prefrontal functioning; Laborde et al., 2018). 
HRV change is expected to be smaller or larger according to the metabolic demands.

Interestingly, studies found evidence that individuals with lower resting HRV make autonomic stress responses to trivial threat cues as if the cues were significant stressors (e.g., Park et al., 2014).

Based on the respective role of tonic and phasic HRV, Laborde et al. $(2017,2018)$ advise researchers to have the following structure in their experimental designs: baseline, event, and post-event. Figure 2 illustrates the tonic and phasic properties of CVC according to three aspects: resting (tonic), reactivity (phasic), and recovery (phasic).

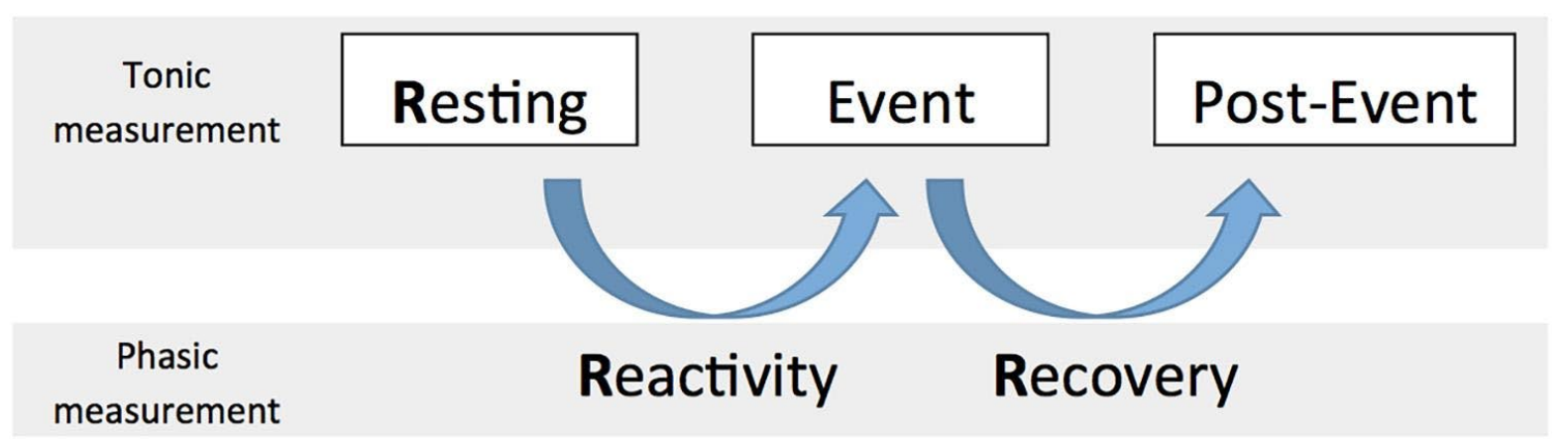

Figure 2. The 3 Rs of cardiac vagal control: Resting, Reactivity, and Recovery. (Source: Laborde, Mosley, \& Mertgen, 2018)

Resting refers to the baseline vagal level usually measured while people are sitting. Higher CVC is commonly linked to better stress management and social functioning. However, many biological processes can become maladaptive when they reach extreme levels, and studies have found a quadratic relationship between CVC and multiple measures of well-being (e.g., Kogan et al., 2013). Reactivity represents the change between baseline and a specific event. Certain phenomena related to self-regulation are accessible only when considering reactivity. For instance, studies found that self-regulation behavior problems among children were not related to resting CVC but only to its reactivity (e.g., Calkins, Graziano, \& Keane, 2007). 
Recovery (also termed "vagal rebound") refers to the change between the event and a time point after the event (i.e., post-event) where measurement would be taken in similar condition to that of the baseline. As emphasized by Laborde et al. (2018), "recovery plays a crucial role regarding the adaptability of the organism, to face an event and then return to resting level". Faster recovery from a cognitive challenge has been linked to enhanced executive functioning (e.g., Kimhy et al., 2013), while prolonged recovery from an emotional challenge has been associated with emotion regulation difficulties (e.g., Neumann, Soller, Thayer, \& Waldstein, 2004).

We conducted a second study using the three Rs structure (Laborde et al., 2017, 2018) to investigate (i) the association between RWA/SDO and tonic HRV for each of the three measurement points (i.e., baseline, event, post-event), (ii) the association between RWA/SDO and phasic HRV (reactivity and recovery). We collected additional psychological and political measures: (i) the degree to which individuals perceive their lives as stressful (perceived stress), the degree to which individuals feel that their cultural identity is threatened by Arabs (perceived cultural threat), (iii) the tendency to reject belief-dissimilar individuals (dogmatic rejection).

A meta-analysis reviewing 208 laboratory studies of acute psychological stressors showed that motivated performance tasks containing both uncontrollable and social-evaluative elements were associated with the largest stress responses and the longest times to recovery (Dickerson \& Kemeny, 2004). Motivated performance tasks are active performance situations that require immediate overt or cognitive responses (e.g., mental arithmetic, speech task; e.g., Blascovich \& Mendes, 2000; Blascovich \& Tomaka, 1996). Social-evaluative threat occurs when poor performance could reveal lack of a highly valued trait such as intelligence or competence (e.g., Kirkpatrick \& Ellis, 2001). Uncontrollability occurs when behavioral responses could not appreciably affect outcomes (forced failure). For our second study, we used a set of three 
forced-failure tasks (LeMoult \& Joormann, 2014). We introduced specific elements that would induce social-evaluative threat: (i) permanent recording of the performance (videotape for subsequent evaluation), and (ii) presence of an evaluative audience during the task (the experimenter present besides the participant).

Based on the evidence presented thus far, it was hypothesized that: (i) RWA/SDO would be associated with lower resting CVC, (2) RWA/SDO would be related to greater autonomic reactivity during stress and thus lower autonomic recovery.

\section{Material and method}

\section{Participants}

Data collection was carried out in two French universities. 198 healthy adults (164 women and 1 non-binary, $\left.M_{\text {age }}=20.32, S D_{\text {age }}=3.19\right)$ volunteered for the experiment. They provided written informed consent before participation. We determined the required sample size through an a priori power analysis (Faul, Erdfelder, Lang, \& Buchner, 2007). We assumed a medium effect size $\left(f^{2}=.15\right)$. The analysis (Linear Multiple Regression: Fixed model, $\mathrm{R}^{2}$ increase with 11 tested predictors) recommended a minimum $N$ of 135 to ensure $90 \%$ power for our design. Because we used five dependent variables, we applied a Bonferroni correction and used a threshold of .01 instead of .05 (.05/5). We used the same exclusion criteria and instructions than for Study 1.

\section{Measures}

\section{Heart rate variability}

The ECG was recorded with the eMotion Faros $180^{\circ}$ device (Mega Electronics, Kuopio, Finland) with a sampling rate of $1000 \mathrm{~Hz}$. Two $\mathrm{Ag}-\mathrm{AgCl}$ electrodes were attached as follows: one electrode (Negative) in the right infraclavicular fossa (just below the rigid clavicle) and 
one electrode (Positive) on the left side of the chest, below the pectoral muscle on the left anterior axillary line.

\section{Questionnaire}

Participants were asked to fill out an online survey including (i) 10 items $(\alpha=.78)$ from the 20-item RWA Scale (Altemeyer, 1988), (ii) 10 items $(\alpha=.83)$ from the 16 -item SDO Scale (Duarte, Dambrun, \& Guimond, 2004), (iii) the 10-item $(\alpha=.81)$ Perceived Stress Scale (PSS; Dupret \& Bocéréan, 2013). Political conservatism was measured using the 15 -item $(\alpha=$ .65) Dogmatic Rejection Scale (DRS; Sgro \& Guimond, 2004). Perceived cultural threat was measured using one item (Dambrun, Maisonneuve, Duarte, \& Guimond, 2002). All responses were collected using visual analogue scales (0-100). All scales are provided in the Appendix.

\section{Procedure}

Baseline $(10 \mathrm{~min})$. We used the same procedure than for Study 1 . When this step ended, the experimenter installed a video camera and announced that an analysis of the subject's nonverbal behaviour during the subsequent tasks would be performed.

Stress $(21 \mathrm{~min}$ ). Participants completed three forced-failure tasks (Forced Failure Paradigm; LeMoult \& Joormann, 2014). The first was a 7-minute emotion recognition task (Tran, Siemer, \& Joormann, 2011). Participants were asked to identify the emotional expression depicted in subliminally presented faces and received a false feedback after each trial $(80 \%$ were negative; $c f$. figure 3). The second was a 7-minute anagram task (van Randenborgh, Hüffmeier, LeMoult, \& Joormann, 2010), with 20 solvable and 8 unsolvable anagrams. Participants were asked to solve as many anagrams as possible, but that they could only work on each anagram for $40 \mathrm{~s}$. A backward counting clock in the upper right corner of the screen reminded participants of the time limit. The third was a 7-minute serial subtraction task (Kirschbaum, Pirke, \& Hellhammer, 1993). Participants were given 5 minutes to count 
backward aloud from 2,083 to zero in 13-step sequences as quickly and accurately as possible. If an error was made, the experimenter would say "error, start again at 2,083." A backward counting clock in the upper right corner of the screen reminded participants of the time limit (5 minutes). During each forced-failure task, the experimenter urged participants to try harder about every 20 seconds ("Concentrate", "Hurry a little", "Please make an effort"). Post-stress $(10 \mathrm{~min}$ ). Participants were asked to rest for 10 minutes (see instructions for resting HRV). Finally, participants were fully debriefed about their experience during the forced-failure tasks. 


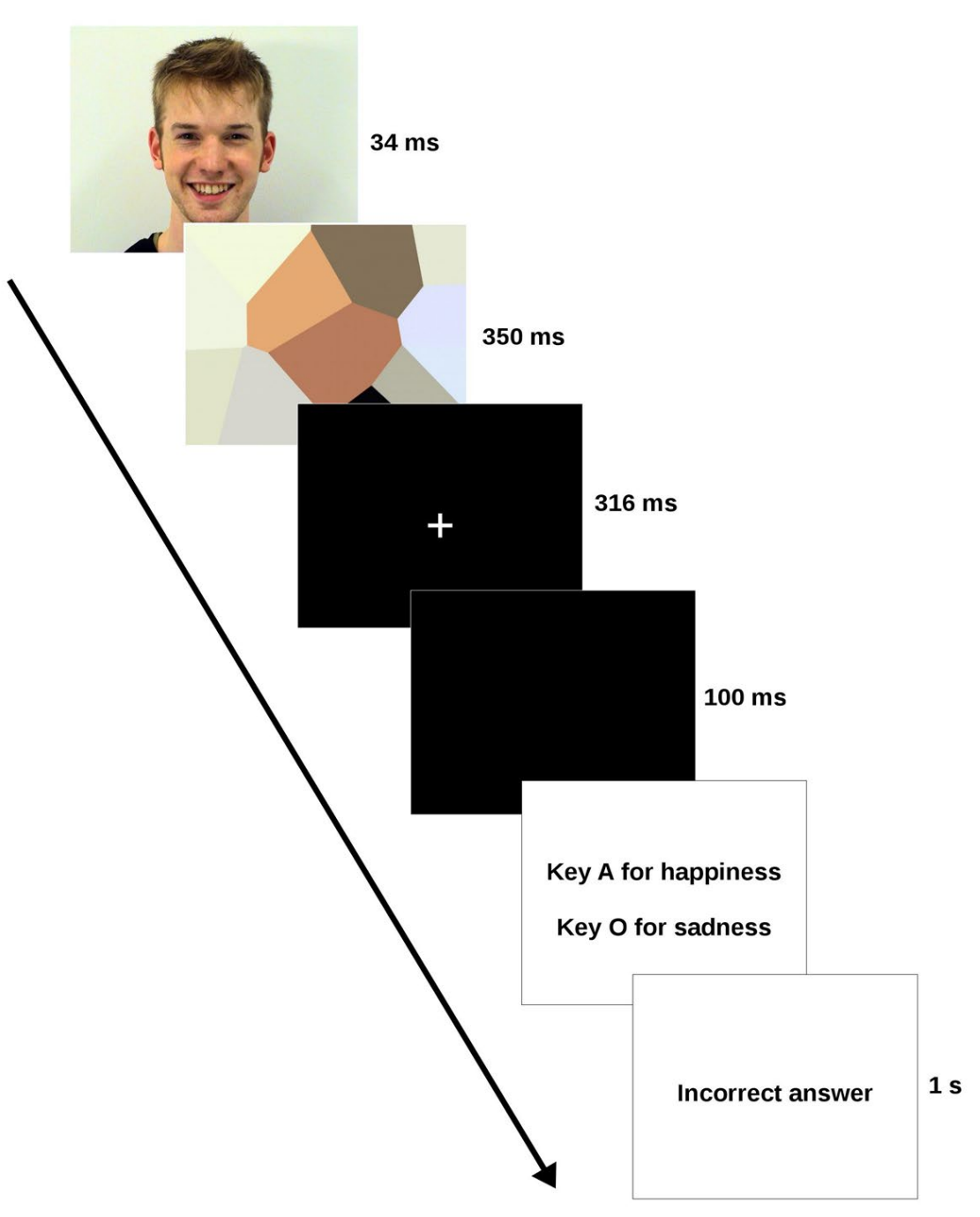

Figure 3. 7-minute emotion recognition task (72 trials). Participants were asked to identify the emotional expression (36 trials for sadness, 36 trials for happiness) of the subliminally presented faces. After each trial, participants received a false feedback on their performance (14 trials with a positive feedback and 58 with a negative feedback). The faces come from the Amsterdam Dynamic Facial Expression Set (Van der Schalk, Hawk, Fischer, \& Doosje, 2011). The set is freely available to investigators for use in scientific research: https://aice.uva.nl/research-tools/adfes-stimulus-set/adfes-stimulus-set.html 


\section{Data analysis}

HRV signals were visually inspected and ectopic (abnormal) heart beats were removed using the automatic correction provided by HRVanalysis 1.1 software (see Pichot, Roche, Celle, Barthélémy, \& Chouchou, 2016). HRVanalysis was used to calculate RMSSD, HF (0.15-0.4 Hz; normalized units) and LF (0.04-0.15 Hz; normalized units). As with study 1, analyses were performed with one main variable indexing vagal tone (RMSSD), but correlations between time and frequency domain parameters were calculated.

We calculated HRV for each of the three measurement points: baseline, stress and post-stress. We also calculated the change between baseline and stress (reactivity HRV) and the change between stress and post-stress (recovery HRV). The hypotheses were tested using multiple linear regression for each outcome (i.e., RWA, SDO, PSS, Perceived cultural threat) ${ }^{3}$, controlling for sex, age, weight, height, alcohol, tobacco consumption, oral and subcutaneous contraception.

Since we observed significant interactions between HRV parameters and data collection site (i.e., site A and site B), we first computed the results for each site, then used a multi-level model to model the random error between the two sites and include all the data. We performed a first set of analyses with tonic HRV as predictor (baseline RMSSD, stress RMSSD, post-stress RMSSD) and a second set with phasic HRV as predictor (reactivity RMSSD, recovery RMSSD). Post-stress RMSSD was added into models on reactivity HRV, while baseline RMSSD was added on models with recovery HRV. For the sake of clarity, we only present significant results.

\footnotetext{
${ }^{3}$ Analyses on the DRS scores were not included in the results section due to low scale reliability $(\alpha=.65)$. However, raw data can be requested from the corresponding author. Overall, we did not observe any influence of HRV on DRS scores.
} 


\section{Results}

Descriptive statistics and Pearson's correlations between HRV parameters are presented in

Table 3. For each of the three measurement points (baseline, stress, post-stress), we observed the expected patterns: parasympathetic parameters (RMSSD, HF) were positively associated with each other; LF was negatively associated with parasympathetic parameters.

Table 3

Descriptive statistics and correlations between heart rate variability parameters $(1=$ baseline, 2 = stress, 3 = post-stress)

\begin{tabular}{|c|c|c|c|c|c|c|c|c|c|}
\hline & 1 & 2 & 3 & 4 & 5 & 6 & 7 & 8 & 9 \\
\hline 1 RMSSD_1 & - & 0.78 & 0.88 & 0.48 & 0.40 & 0.50 & -0.42 & -0.30 & -0.43 \\
\hline 2 RMSSD_2 & & - & 0.81 & 0.36 & 0.48 & 0.42 & -0.33 & -0.29 & -0.38 \\
\hline 3 RMSSD_3 & & & - & 0.38 & 0.35 & 0.51 & -0.36 & -0.29 & -0.50 \\
\hline 4 HF_1 & & & & - & 0.54 & 0.65 & -0.91 & -0.55 & -0.61 \\
\hline 5 HF_2 & & & & & - & 0.51 & -0.49 & -0.59 & -0.48 \\
\hline $6 \mathrm{HF}_{-} 3$ & & & & & & - & -0.58 & -0.43 & -0.83 \\
\hline 7 LF_1 & & & & & & & - & 0.53 & 0.62 \\
\hline 8 LF_2 & & & & & & & & - & 0.46 \\
\hline 9 LF_3 & & & & & & & & & - \\
\hline$M(\mathrm{SD})$ & $\begin{array}{c}37.17 \\
(22.08)\end{array}$ & $\begin{array}{c}41.82 \\
(20.45)\end{array}$ & $\begin{array}{c}43.83 \\
(22.76)\end{array}$ & $\begin{array}{c}32.49 \\
(17.90)\end{array}$ & $\begin{array}{c}28.43 \\
(10.96)\end{array}$ & $\begin{array}{c}30.61 \\
(16.50)\end{array}$ & $\begin{array}{c}58.76 \\
(19.54)\end{array}$ & $\begin{array}{c}53.38 \\
(13.17)\end{array}$ & $\begin{array}{c}59.64 \\
(18.43)\end{array}$ \\
\hline
\end{tabular}

Note. $\mathrm{RMSSD}=$ root mean square of successive R-R differences; $\mathrm{HF}=$ high frequencies $(0.15-0.4 \mathrm{~Hz})$ expressed in normalized units; $\mathrm{LF}=$ low frequencies $(0.04-0.15 \mathrm{~Hz})$ expressed in normalized units. 
Descriptive statistics and Pearson's correlations between self-reported measures are provided in Table 4. RWA, SDO and perceived cultural threat were positively correlated.

Table 4

Descriptive statistics and correlations between self-reported measures

\begin{tabular}{lcccc}
\hline & 1 & 2 & 3 & 4 \\
\hline 1 RWA & - & 0.42 & 0.17 & 0.41 \\
2 SDO & & - & 0.12 & 0.36 \\
3 PSS & & & - & 0.10 \\
4 Threat & & & & - \\
$M(\mathrm{SD})$ & $21.1(13.7)$ & $14.6(14)$ & $46.71(18.3)$ & $12.3(22.3)$ \\
\hline
\end{tabular}

Note. $\mathrm{RWA}=$ right-wing authoritarianism; $\mathrm{SDO}=$ social dominance orientation; $\mathrm{PSS}=$ perceived stress scale.

\section{Tonic HRV and self-reported measures}

RWA scores were regressed on tonic HRV at baseline, stress and post-stress. For site 1, RMSSD at stress significantly predicted RWA scores. SDO scores were also regressed on tonic HRV at baseline, stress and post-stress. For site 1, RMSSD at stress significantly predicted SDO scores (see Table 5) ${ }^{4}$. Taken together, the regression analyses suggest that higher RWA/SDO scores were associated with lower tonic HRV during the forced-failure tasks.

\footnotetext{
${ }^{4}$ For all analyses, we found a main effect of alcohol, showing that participant who reported not drinking alcohol had higher RWA scores. Because this is not the main focus of this paper, this will not be discussed here, but estimates are available on demand, or can be computed from the raw data.
} 
Table 5

Multiple linear regressions examining the associations between tonic HRV and self-reported measures (site 1)

$\begin{array}{llcccc}\text { Criterion variables } & \text { Predictor variable } & \beta & F & p & 95 \% \mathrm{CI} \\ & & & & & \\ \text { RWA } & \text { RMSSD (stress) } & -0.46 & 5.6 & .02 & {[-.86,-.07]} \\ \text { SDO } & \text { RMSSD (stress) } & -0.45 & 5.6 & .02 & {[-.83,-.07]}\end{array}$

Note. $\mathrm{HRV}=$ heart rate variability; RWA = right-wing authoritarianism; $\mathrm{SDO}=$ social dominance orientation; RMSSD = root mean square of successive R-R differences.

\section{Phasic HRV and self-reported measures}

RWA scores were regressed on phasic HRV (reactivity RMSSD and recovery RMSSD). For site 1, reactivity RMSSD and recovery RMSSD significantly predicted RWA scores. SDO scores were also regressed on phasic HRV (reactivity RMSSD and recovery RMSSD). For site 1 , reactivity and recovery RMSSD significantly predicted SDO scores (see Table 6). These regression analyses suggest that higher RWA/SDO scores were associated with higher reactivity and lower recovery. 
Table 6

Multiple linear regressions examining the associations between phasic HRV and self-reported measures (site 1)

$\begin{array}{lccccc}\text { Criterion variables } & \text { Predictor variable } & \beta & F & p & 95 \% \text { CI } \\ & \text { RWA } & & & & \\ & \text { Reactivity RMSSD } & 0.41 & 4.64 & .03 & {[-.09, .29]} \\ & \text { Recovery RMSSD } & -0.40 & 5.55 & .02 & {[-.74,-.06]} \\ \text { SDO } & \text { Reactivity RMSSD } & .40 & 4.79 & .03 & {[.03, .77]} \\ & \text { Recovery RMSSD } & -0.43 & 7.46 & .008 & {[-.77,-.11]}\end{array}$

Note $. \mathrm{HRV}=$ heart rate variability; RWA $=$ right-wing authoritarianism; $\mathrm{SDO}=$ social dominance orientation; RMSSD = root mean square of successive R-R differences. 


\section{Discussion}

Prior research suggests a relation between self-regulatory control/threat processing and authoritarian attitudes. However, no studies on authoritarianism have used PNS functioning as a physiological index of self-regulation to explore this relation. PNS functioning is commonly assessed by examining tonic HRV and phasic HRV. A plethora of studies have shown that higher resting HRV contributes to adaptive and flexible responses to situational demands (e.g., Park et al., 2014). Reactivity HRV reflects the organism's ability to engage and disengage with the environment (reactivity is expected to be smaller or larger according to the metabolic demands.), while recovery plays a crucial role in returning to resting level after an event (Laborde et al., 2018).

We first investigated the association between authoritarian attitudes and tonic HRV and found that high RWA was associated with lower resting HRV (Study 1). We observed a marginal relation between resting HRV and SDO, suggesting that high SDO was also associated with lower resting HRV. In our second study, stress-induced autonomic reactivity was examined as a potential pathway linking authoritarian attitudes to self-regulation. Results showed that high RWA and high SDO were associated (i) with lower tonic HRV during stress, (ii) with greater autonomic reactivity during stress. Autonomic post-stress recovery was also examined given that prolonged post-stress recovery could be another important linkage between authoritarian attitudes and self-regulation. We found that high RWA and high SDO were associated with lower autonomic recovery. These results suggest that autonomic dysregulation during and following stress is a plausible physiological pathway connecting RWA and SDO to selfregulation.

Our results are consistent with previous research linking authoritarian attitudes to threat sensitivity. A number of studies have shown that (i) when exposed to social threats, high RWA individuals show heightened reactivity and more motivation to control the threat (e.g., 
Feldman et al., 2010), and (ii) when exposed to competitive threats, high SDO individuals react with increased greed and effort to win at all costs (e.g., Cozzolino \& Snyder, 2008).

\section{Anger and autonomic recovery}

Lower autonomic recovery could be due to the greater tendency for authoritarian individuals to experience anger (e.g., Jost, 2019; Kossowska, Bukowski, \& Van Hiel, 2008). Anger typically arises within agonistic contexts and studies found that this emotion is associated with delayed autonomic recovery (e.g., Anderson, Linden, \& Habra, 2005; Engebretson, Matthews, \& Scheier, 1989; Salomon, Burgess, \& Bosson, 2015; Vella \& Friedman, 2009). An explanation of why anger is associated with delayed recovery may involve rumination (Suchday, Carter, Ewart, Larkin, \& Desiderato, 2004). Rumination can be defined as thoughts that focus one's attention on negative mood, the causes and consequences of the mood, and self-evaluations related to the mood (Gerin, Davidson, Christenfeld, Goyal, \& Schwartz, 2006). The authors found that high trait ruminators had the poorest autonomic recovery. Thus, post-stress anger-related thoughts could be responsible for lower autonomic recovery among high RWA/SDO individuals.

\section{Autonomic flexibility and authoritarian attitudes}

Our results suggest that authoritarian attitudes are primarily associated with the phasic component of CVC (overall we found poor evidence that both RWA and SDO are related to baseline HRV). Polyvagal theory and the neurovisceral integration model acknowledge the role of phasic HRV in flexible adaptation to situational demands (Porges, 2007; Thayer et al., 2009). Autonomic flexibility allows for rapid modulation of physiological states in accordance with situational demands. In contrast, autonomic rigidity results in a lessened capacity to alter physiological responses in synchrony with environmental changes (e.g., Appelhans \& Luecken, 2006). Both theories also acknowledge the role of vagal reactivity in 
adaptation. Polyvagal theory causally relates autonomic flexibility with emotion-related selfregulation and prosocial tendencies. Following a polyvagal perspective, our results suggest that autonomic rigidity may be a core feature by which we may understand RWA and SDO. An invalid neuroception of danger associated with a reduced capacity to alter autonomic responses in synchrony with situational demands may underlie the psychological motivations to endorse authoritarian beliefs. The model of neurovisceral integration leads to a similar conclusion: chronic difficulties in inhibiting the default response mode to threat would cause to individuals to endorse authoritarian attitudes. The polyvagal theory and the neurovisceral integration model approaches also causally relate CVC to social behaviors, thus providing insights on how political attitudes may affect concrete behavior.

\section{Prejudice and discrimination}

Why RWA and SDO cause prejudice and discrimination remains an open question (e.g., Kteily, Sidanius, \& Levin., 2011). Pratto et al. (1994) proposed that decreased inclusiveness and empathic concern among high SDO individuals play important roles. As mentioned previously, studies found that autonomic flexibility is associated with calming and selfsoothing (e.g., Porges, 2007), and sympathy and compassion for the others in need (e.g., Stellar et al., 2015). Keltner, Kogan, Piff and Saturn (2014) states that "the relationship between vagus nerve activation and prosocial behavior is driven, in part, by a reduction in arousal, which enables a shift in attention to the person in need". This is in line with research showing that low CVC is associated with rigid attentional bias toward threat-related stimuli (e.g., Park \& Thayer, 2014). Thus, a reduced capacity to inhibit the sympatho-excitatory circuits responsible for default threat responses: (i) may limit the ability for authoritarian individuals to challenge invalid threat perception, to pay attention to distress cues from the others, and to display sympathetic responses; and (ii) may promote punitive attitudes and aggressive behaviors toward specific outgroups in ways favoring the perpetuation of 
conventional values and hierarchical arrangements amongst these groups. By contrast, the ability to inhibit the default response mode to threat and to focus on a broader set of social cues may increase flexibility by decreasing stress levels and facilitate prosocial tendencies (e.g., empathic concern, inclusiveness, tolerance).

\section{Interactions between HRV parameters and data collection site}

We found heterogeneity in our data depending on the site in which they were collected. Specifically, although we do not observe any significant difference between the HRV parameters between site 1 and site 2, we found that the average scores as well as the average variances of RWA and SDO were higher at site 1 than at site 2 . We believe that this may be a viable explanation for the fact that we observe a weaker relationship between HRV and authoritarian attitudes on site 2 . Thus, the attitude scores at site 2 are may be subject to a ceiling effect, which makes it difficult to highlight a relationship between RWA/SDO and HRV.

\section{Causal relationships between $\mathrm{CVC}$ and authoritarian attitudes}

Because we did not experimentally provoke HRV level, it will be essential to test causal relationships between CVC and RWA/SDO. Studies have found a positive association between tonic HRV and phasic HRV (i.e., greater baseline HRV has been associated with adaptive autonomic reactivity and reduced post-stress recovery; e.g., Weber et al., 2010) and several techniques exist for experimentally inducing changes in baseline HRV, as is the case with pharmacological blockade and biofeedback training (e.g., Lehrer \& Gevirtz, 2014).

Genetic factors show substantial contribution to ANS functioning, but environmental factors may explain 40 to $64 \%$ of variance (Singh et al., 1999). Berna, Ott, and Nandrino (2014) proposed that baseline HRV could be a consequence of prolonged and/or repeated autonomic stress responses associated with emotional or stressful situations: HRV recovery level 
decreases over a longer time and the baseline HRV level diminishes gradually. Interestingly, it has been proposed that higher HRV could be responsible for improved social functioning and that increased social functioning could enhance HRV (e.g., Kok \& Fredrickson, 2010). The authors found an "upward spiral" in which HRV "facilitates capitalizing on social and emotional opportunities and the resulting opportunistic gains, in turn, lead to higher vagal tone". Thus, authoritarian attitudes and CVC could reciprocally and prospectively predict one another. This is in line with the dynamic, recursive theoretical framework defined by Jost, Nam, Amodio, and van Bavel (2014) in which "differences in neurocognitive structure and functioning are linked to a constellation of social and psychological processes that unfold over time and both reflect and give rise to the expression of political behavior."

\section{Conclusion}

A multitude of studies have demonstrated the importance of RWA and SDO as two basic dimensions of individual differences in political attitudes. Seeing authoritarian attitudes through the lens of self-regulation has been spurred by research linking self-regulatory control and threat processing with ideology. Allport (1954) argued that authoritarianism is characterized by insecurity and fearfulness. These feelings would cause the authoritarian personality (i) to need structure, order and control in their social environments, and (ii) to react with punitive hostility to unconventionality, novelty and change. Rokeach (1954) preferred the concept of "dogmatism" defined as "a relatively closed cognitive organization of beliefs and disbeliefs about reality". Because of such a cognitive configuration, dogmatic individuals should experience difficulty in dealing with new information that challenges their existing beliefs. Dogmatic individuals should also feel hostility and reject persons and outgroups with dissimilar beliefs and values to their own. Wilson (1973) defined conservatism as a "generalized susceptibility to experiencing threat or anxiety in the face of uncertainly". Amodio et al. (2007) proposed that political orientation "reflects individual differences in the 
functioning of a general mechanism related to cognitive control and self-regulation". Unfortunately, biologically independent variables are extremely rare in research on RWA and SDO, and biological theories are rarely used to generate hypotheses about political attitudes. As emphasized by Hatemi and McDermott (2011), "who we are and what we do is the product of environmental and biological factors" and human political behavior "does not transcend biology even as it is not determined by biology". To our knowledge, the present research is the first to explore the relationship between authoritarian attitudes and CVC, suggesting that one organizing element of the many psychological and physiological traits related to RWA and SDO may be hyper-vigilance to threat-related stimuli and dampened capacity to face stress (i.e., autonomic dysregulation during and following stress). The presents study also highlights that biology "can help to account both for central behavioral tendencies and also for the astounding variation around these central tendencies" (Hatemi \& McDermott, 2011). 


\section{References}

Allport, G. W. (1954). The nature of prejudice. Cambridge, MA: Perseus Books.

Altemeyer, B. (1981). Right-wing authoritarianism. Winnipeg, Canada: University of Manitoba Press.

Altemeyer, B. (1988). Enemies of freedom: Understanding right-wing authoritarianism. San Francisco: Jossey-Bass.

Altemeyer, B. (1996). The Authoritarian Specter. Cambridge: Harvard University Press.

Altemeyer, B. (1998). The other "authoritarian personality.” In L. Berkowitz (Ed.), Advances in experimental social psychology (Vol. 30, pp. 47-92). Orlando, FL: Academic Press.

Amodio, D. M., Jost, J. T., Master, S. L., \& Yee, C. M. (2007). Neurocognitive correlates of liberalism and conservatism. Nature Neuroscience, 10(10), 1246-1247. doi:10.1038/nn1979

Anderson, J. C., Linden, W., \& Habra, M. E. (2005). The importance of examining blood pressure reactivity and recovery in anger provocation research. International Journal of Psychophysiology, 57(3), 159-163. doi:10.1016/j.ijpsycho.2004.12.011

Appelhans, B. M., \& Luecken, L. J. (2006). Heart rate variability as an index of regulated emotional responding. Review of General Psychology, 10(3), 229-240. doi:10.1037/1089-2680.10.3.229

Berna, G., Ott, L., \& Nandrino, J. L.(2014). Effects of emotion regulation difficulties on the tonic and phasic cardiac autonomic response. Plos One, 9:e102971. doi:10.1371/journal.pone.0102971

Blascovich, J., \& Mendes, W. B. (2000). Challenge and threat appraisals: The role of affective cues. In J. Forgas (Ed.), Feeling and thinking: The role of affect in social cognition (pp. 59-82). Cambridge, England: Cambridge University Press. 
Blascovich, J., \& Tomaka, J. (1996). The biopsychosocial model of arousal regulation. Advances in Experimental Social Psychology, 28, 1-51. doi:10.1016/S00652601(08)60235-X

Brosschot, J. F., Verkuil, B., \& Thayer, J. F. (2016). The default response to uncertainty and the importance of perceived safety in anxiety and stress: an evolution-theoretical perspective. Journal of Anxiety Disorders, 41, 22-34. doi:10.1016/j.janxdis.2016.04.012

Brosschot, J. F., Verkuil, B., \& Thayer, J. F. (2018). Generalized Unsafety Theory of Stress: Unsafe Environments and Conditions, and the Default Stress Response. International Journal of Environmental Research and Public Health, 15(3): e464. doi:10.3390/ijerph15030464

Calkins, S. D., Graziano, P. A., \& Keane, S. P. (2007). Cardiac vagal regulation differentiates among children at risk for behavior problems. Biological Psychology, 74, 144-153. doi:10.1016/j.biopsycho.2006.09.005

Cozzolino, P. J., \& Snyder, M. (2008). Good Times, Bad Times: How Personal Disadvantage Moderates the Relationship Between Social Dominance and Efforts to Win. Personality and Social Psychology Bulletin, 34(10), 1420-1433. doi:10.1177/0146167208321595

Dambrun, M., Maisonneuve, C., Duarte, S., \& Guimond, S. (2002). Modélisation de quelques déterminants psychosociaux de l'attitude envers l'extrême droite. Les Cahiers Internationaux de Psychologie Sociale, 55, 49-63.

Danso, H. A., \& Esses, V. M. (2001). Black experimenters and the intellectual test performance of White participants: The tables are turned. Journal of Experimental Social Psychology, 37(2), 158-165. doi:10.1006/jesp.2000.1444

Dickerson, S. S., \& Kemeny, M. E. (2004). Acute stressors and cortisol responses: a theoretical integration and synthesis of laboratory research. Psychological Bulletin, 130(3), 355-391. doi:10.1037/0033-2909.130.3.355 
Duarte, S., Dambrun, M., \& Guimond, S. (2004). La dominance sociale et les « mythes légitimisateurs » : validation française de l'échelle d'orientation à la dominance sociale. Revue Internationale de Psychologie Sociale, 17, 97-126.

Duckitt, J. (2001). A dual-process cognitive-motivational theory of ideology and prejudice. In M. P. Zanna (Ed.), Advances in Experimental Social Psychology (Vol. 33, pp. 41-113). New York: Academic Press.

Duckitt, J., \& Sibley, C. G. (2010). Personality, ideology, prejudice, and politics: A dual process motivational model. Journal of Personality, 78(6), 1861-1894. doi:10.1111/j.1467-6494.2010.00672.x

Duckitt, J., \& Sibley, C. G. (2017). The dual process motivational model of ideology and prejudice. In C. G. Sibley \& F. K. Barlow (Eds.), The Cambridge handbook of the psychology of prejudice (pp. 188-221). New York, NY, US: Cambridge University Press.

Dupret, E., \& Bocéréan, C. (2013). La mesure du stress en milieu professionnel avec l'échelle de stress perçu (Perceived Stress Scale): pertinence des versions en dix et quatre items. Psychologie du Travail et des Organisations, 19(4), 362-384. doi:10.1016/S14202530(16)30049-8

Eibach, R. P., \& Keegan, T. (2006). Free at last? Social dominance, loss aversion, and white and black Americans' differing assessments of racial progress. Journal of Personality and Social Psychology, 90(3), 453-467. doi:10.1037/0022-3514.90.3.453

Engebretson, T. O., Matthews, K. A., \& Scheier, M. F. (1989). Relations between anger expression and cardiovascular reactivity: Reconciling inconsistent findings through a matching hypothesis. Journal of Personality and Social Psychology, 57(3), 513-521. doi:10.1037/0022-3514.57.3.513

Fabes, R. A., \& Eisenberg, N. (1997). Regulatory control and adults' stress-related responses to daily life events. Journal of Personality and Social Psychology, 73(5), 1107-1117. 
Retrieved from

http://www.researchgate.net/profile/Nancy_Eisenberg/publication/13864629_Regulatory _control_and_adults\%27_stress

related_responses_to_daily_life_events/links/02e7e539be941aade6000000.pdf

Faul, F., Erdfelder, E., Lang, A. G., \& Buchner, A. (2007). G*Power 3: A flexible statistical power analysis program for the social, behavioral, and biomedical sciences. Behavior Research Methods, 39, 175-191. doi:10.3758/BF03193146

Feldman, S., Lavine, H., Lodge, M., \& Verhulst, B. (2010). Seeing Negative:

Authoritarianism and Automatic Vigilance for Threatening Stimuli. Paper presented at the Annual Meeting of the International Society of Political Psychology, San Francisco, CA.

Geisler, F. C. M., Kubiak, T., Siewert, K., \& Weber, H. (2013). Cardiac vagal tone is associated with social engagement and self-regulation. Biological Psychology, 93, 279 286. doi:10.1016/j.biopsycho.2013.02.013

Gerin, W., Davidson, K. W., Christenfeld, N. J., Goyal, T. \& Schwartz, J. E. (2006). The Role of Angry Rumination and Distraction in Blood Pressure Recovery from Emotional Arousal. Psychosomatic Medicine, 68, 64-72. doi:10.1097/01.psy.0000195747.12404.aa

Ghuman, N., Campbell, P., \& White, W. B. (2009). Role of ambulatory and home blood pressure recording in clinical practice. Current Cardiology Reports, 11(6), 414-421. doi:10.1007/s11886-009-0060-6

Grossman, P., \& Taylor, E. W. (2007). Toward understanding respiratory sinus arrhythmia: relations to cardiac vagal tone, evolution and biobehavioral functions. Biological Psychology, 74, 263-285. doi:10.1016/j.biopsycho.2005.11.014

Hatemi, P. K., \& McDermott, R. (2011). Evolution as a Theory for Political Behavior. In P. K. Hatemi \& R. McDermott (Eds.), Man is by Nature a Political Animal: Evolution, Biology, and Politics. (pp. 13-46). Chicago, IL: University of Chicago Press. 
Hatemi, P. K., Gillespie, N. A., Eaves, L. J., Maher, B. S., Webb, B. T., Heath, A. C., Medland, S. E., Smyth, D. C., Beeby, H. N., Gordon, S. D., Montgomery, G. W., Zhu, G., Byrne, E. M., \& Martin, N. G. (2011). A genome-wide analysis of liberal and conservative political attitudes. Journal of Politics, 73(1), 1-15. doi:10.1017/S0022381610001015

Heathers, J. A. (2014). Everything Hertz: methodological issues in short-term frequencydomain HRV. Frontiers in Physiology, 5, 177. doi:10.3389/fphys.2014.00177

Heatherton, T. F., \& Wagner, D. D. (2011). Cognitive neuroscience of self-regulation failure. Trends in Cognitive Sciences, 15, 132-139. doi:10.1016/j.tics.2010.12.005

Henry, P. J., Sidanius, J., Levin, S., \& Pratto, F. (2005). Social dominance orientation, authoritarianism, and support for intergroup violence between the Middle East and America. Political Psychology, 26, 569-583.

Hibbing, J. R., Smith, K. B., \& Alford, J. R. (2014). Differences in negativity bias underlie variations in political ideology. Behavioral and Brain Sciences, 37(3), 297-350. doi:10.1017/S0140525X13001192

Hodson, G., Hogg, S. M., \& MacInnis, C. C. (2009). The role of 'dark personalities' (narcissism, Machiavellianism, psychopathy), Big Five personality factors, and ideology in explaining prejudice. Journal of Research in Personality, 43(4), 686-690. doi:10.1016/j.jrp.2009.02.005

Huang, L. L., \& Liu, J. H. (2005). Personality and social structural implications of the situational priming of social dominance orientation. Personality and Individual Differences, 38(2), 267-276. doi:10.1016/j.paid.2004.04.006

Iorfino, F., Alvares, G. A., Guastella, A. J., \& Quintana, D. S. (2015). Cold face test-induced increases in heart rate variability are abolished by engagement in a social cognition task. Journal of Psychophysiology, 30(1), 38-46. doi:10.1027/0269-8803/a000152 
Jost, J. (2019). Anger and Authoritarianism Mediate the Effects of Fear on Support for the Far Right—What Vasilopoulos et al. (2019) Really Found. Political Psychology, 40(4), 705711. doi:10.1111/pops. 12567

Jost, J. T., Glaser, J., Kruglanski, A. W. \& Sulloway, F. (2003). Political conservatism as motivated social cognition. Psychological Bulletin, 129(3), 339-375. doi:10.1037/00332909.129.3.339

Jost, J. T., Nam, H. H., Amodio, D. M., \& Van Bavel, J. J. (2014). Political neuroscience: The beginning of a beautiful friendship. Advances in Political Psychology, 35(S1), 3-42. doi:10.1111/pops. 12162

Kanai, R., Feilden, T., Firth, C. \& Rees, G. (2011). Political orientations are correlated with brain structure in young adults. Current Biology, 21(8), 677-680. doi:10.1016/j.cub.2011.03.017

Keltner, D., Kogan, A., Piff, P. K., \& Saturn, S. R. (2014). The sociocultural appraisals, values, and emotions (SAVE) framework of prosociality: core processes from gene to meme. Annual Review of Psychology, 65, 425-460. doi:10.1146/annurev-psych-010213115054

Kemp, A. H., Quintana, D. S., Felmingham, K. L., Matthews, S., \& Jelinek, H. F. (2012). Depression, comorbid anxiety disorders, and heart rate variability in physically healthy, unmedicated patients: implications for cardiovascular risk. Plos One, 7(2), e30777.

Kimhy, D., Crowley, O. V., McKinley, P. S., Burg, M. M., Lachman, M. E., Tun, P. A., et al. (2013). The association of cardiac vagal control and executive functioning - findings from the MIDUS study. Journal of Psychiatric Research, 47, 628-635. doi:10.1016/j.jpsychires.2013.01.018

Kirkpatrick, L. E., \& Ellis, B. J. (2001). An evolutionary-psychological approach to selfesteem: Multiple domains and multiple functions. In G. Fletcher \& M. Clark (Eds.), The 
Blackwell handbook of social psychology: Vol. 2. Interpersonal processes (pp. 411-436). Oxford, England: Blackwell.

Kirschbaum, C., Pirke, K.-M., \& Hellhammer, D. H. (1993). The “Trier Social Stress Test”- a tool for investigating psychobiological stress responses in a laboratory setting. Neuropsychobiology, 28(1-2), 76-81. doi:10.1159/000119004

Kogan, A., Gruber, J., Shallcross, A. J., Ford, B. Q., \& Mauss, I. B. (2013). Too much of a good thing? Cardiac vagal tone's nonlinear relationship with well-being. Emotion, 13, 599-604. doi:10.1037/a0032725

Kok, B. E., \& Fredrickson, B. L. (2010). Upward spirals of the heart: Autonomic flexibility, as indexed by vagal tone, reciprocally and prospectively predicts positive emotions and social connectedness. Biological Psychology, 85(3), 432-436. doi:10.1016/j.biopsycho.2010.09.005

Kossowska, M., Bukowski, M., \& Van Hiel, B. (2008). The impact of submissive and dominant authoritarianism and negative emotions on prejudice. Personality and Individual Differences, 45(8), 744-749. doi:10.1016/j.paid.2008.07.022

Kossowska, M., \& Van Hiel, A. (2003). The Relationship Between Need for Closure and Conservative Beliefs in Western and Eastern Europe. Political Psychology, 24(3), 501518. doi:10.1111/0162-895X.00338

Kteily, N., Bruneau, E., Waytz, A., \& Cotterill, S. (2015). The ascent of man: Theoretical and empirical evidence for blatant dehumanization. Journal of Personality and Social Psychology, 109(5), 901-931. doi:10.1037/pspp0000048

Kteily, N. S., Sidanius, J., \& Levin, S. (2011). Social dominance orientation: Cause or "mere effect"? Evidence for SDO as a causal predictor of prejudice and discrimination against ethnic and racial outgroups. Journal of Experimental Social Psychology, 47(1), 208-214. doi:10.1016/j.jesp.2010.09.009 
Laborde, S., Mosley, E., \& Mertgen, A. (2018). Vagal Tank Theory: The Three Rs of Cardiac Vagal Control Functioning - Resting, Reactivity, and Recovery. Frontiers in Neuroscience, 12, 458. doi:10.3389/fnins.2018.00458

Laborde, S., Mosley, E., \& Thayer, J. F. (2017). Heart rate variability and cardiac vagal tone in psychophysiological research-Recommendations for experiment planning, data analysis, and data reporting. Frontiers in Psychology, 8, Article 213. doi:10.3389/fpsyg.2017.00213

Larsson, M. R., Björklund, F., \& Bäckström, M. (2012). Right-wing authoritarianism is a risk factor of torture-like abuse, but so is social dominance orientation. Personality and Individual Differences, 53(7), 927-929. doi:10.1016/j.paid.2012.06.015

Lehrer, P. M. (2013). How does heart rate variability biofeedback work? resonance, the baroreflex, and other mechanisms. Biofeedback, 41, 26-31. doi:10.5298/1081-593741.1.02

Lehrer, P. M., \& Gevirtz R. (2014). Heart rate variability biofeedback: how and why does it work? Frontiers in Psychology, 5, 756. doi:10.3389/fpsyg.2014.00756

LeMoult, J., \& Joormann, J. (2014). Depressive rumination alters cortisol decline in Major Depressive Disorder. Biological Psychology, 100, 50-55. doi:10.1016/j.biopsycho.2014.05.001

Ludeke, S. G., \& Krueger, R. F. (2013). Authoritarianism as a personality trait: Evidence from a longitudinal behavior genetic study. Personality and Individual Differences, 55(5), 480484. doi:10.1016/j.paid.2013.04.015

McCraty, R., \& Childre, D. (2010). Coherence: bridging personal, social, and global health. Alternative Therapies in Health and Medicine, 16, 10-24.

McFarland, S. (2010). Authoritarianism, social dominance, and other roots of generalized prejudice. Political Psychology, 31, 453-477. doi:10.1111/j.1467-9221.2010.00765.x 
Melzig, C. A., Weike, A. I., Hamm, A. O., \& Thayer, J. F. (2009). Individual differences in fear potentiated startle as a function of resting heart rate variability: Implications for panic disorder. International Journal of Psychophysiology, 71(2), 109-117. doi:10.1016/j.ijpsycho.2008.07.013

Messerotti Benvenuti, S., Mennella, R., Buodo, G., and Palomba, D. (2015). Dysphoria is associated with reduced cardiac vagal withdrawal during the imagery of pleasant scripts: evidence for the positive attenuation hypothesis. Biological Psychology, 106, 28-38. doi:10.1016/j.biopsycho.2014.11.017

Montano, N., Porta, A., \& Malliani, M. (2001). Evidence for Central Organization of Cardiovascular Rhythms. Annals of the New York Academy of Sciences, 940(1), 299-306. doi:10.1111/j.1749-6632.2001.tb03685.x

Morrison, K. R., \& Ybarra, O. (2008). The effects of realistic threat and group identification on social dominance orientation. Journal of Experimental Social Psychology, 44(1), 156163. doi:10.1016/j.jesp.2006.12.006

Movius, H. L., \& Allen, J. J. B. (2005). Cardiac vagal tone, defensiveness, and motivational style. Biological Psychology, 68(2), 147-162. doi:10.1016/j.biopsycho.2004.03.019

Neumann, S. A., Sollers, J. J., Thayer, J. F., \& Waldstein, S. R. (2004). Alexithymia predicts attenuated autonomic reactivity, but prolonged recovery to anger recall in young women. International Journal of Psychophysiology, 53, 183-195.

Negrao, B. L., Bipath, P., Van der Westhuizen, D., \& Viljoen, M. (2011). Autonomic correlates at rest and during evoked attention in children with attention-deficit/hyperactivity disorder and effects of methylphenidate. Neuropsychobiology, 63(2), 82-91. doi:10.1159/000317548

Otzenberger, H., Gronfier, C., Simon, C., Charloux, A., Ehrhart, J., Piquard, F., \& Brandenberger, G. (1998). Dynamic heart rate variability: a tool for exploring 
sympathovagal balance continuously during sleep in men. The American Journal of Physiology, 275(3 pt 2), H946-H950. Retrieved from

http://ajpheart.physiology.org/content/275/3/H946.long

Oxley, D. R., Smith, K. B., Alford, J. R., Hibbing, M. V., Miller, J. L., Scalora, M., Hatemi, P. K., \& Hibbing, J. R. (2008). Political attitudes vary with physiological traits. Science, 321(5896), 1667-1670. doi:10.1126/science.1157627

Pagani, M., Lombardi, F., Guzzetti, S., Rimoldi, O., Furlan, R., Pizzinelli, P., et al. (1986). Power spectral analysis of heart rate and arterial pressure variabilities as a marker of sympatho-vagal interaction in man and conscious dog. Circulation Research, 59(2), 178193. doi:10.1161/01.RES.59.2.178

Pappens, M., Schroijen, M., Sutterlin, S., Smets, E., Van den Bergh, O., Thayer, J. F., \& Van Diest, I. (2014). Resting Heart Rate Variability Predicts Safety Learning and Fear Extinction in an Interoceptive Fear Conditioning Paradigm. Plos One, 9(9). doi:10.1371/journal.pone.0105054

Park, G., \& Thayer, J. F. (2014). From the heart to the mind: cardiac vagal tone modulates top-down and bottom-up visual perception and attention to emotional stimuli. Frontiers in Psychology, 5, 278. doi:10.3389/fpsyg.2014.00278

Park, G., Vasey, M., Van Bavel, J. J., \& Thayer, J. F. (2013). Cardiac vagal tone is correlated with selective attention to neutral distractors under load. Psychophysiology, 50(4), 398406. doi:10.1111/psyp.12029

Pichot, V., Roche, F., Celle, S., Barthélémy, J. C., \& Chouchou, F (2016). HRVanalysis: A Free Software for Analyzing Cardiac Autonomic Activity. Frontiers in Physiology, 7, 557. doi:10.3389/fphys.2016.00557

Porges, S. W. (1992). Vagal tone: A physiological marker of stress vulnerability. Pediatrics, 90(3), 498-504. Retrieved from 
http://www.researchgate.net/publication/21641337_Vagal_tone_a_physiologic_marker_o f_stress_vulnerability

Porges, S. W. (2007). The polyvagal perspective. Biological Psychology, 74(2), 116-143. doi:10.1016/j.biopsycho.2006.06.009

Pratto, F., Sidanius, J., \& Levin, S. (2006). Social dominance theory and the dynamics of intergroup relations: Taking stock and looking forward. European Review of Social Psychology, 17(1), 271-320. doi:10.1080/10463280601055772

Pratto, F., Sidanius, J., Stallworth, L. M., \& Malle, B. F. (1994). Social dominance orientation: A personality variable predicting social and political attitudes. Journal of Personality and Social Psychology, 67(4), 741-763. doi:10.1037/0022-3514.67.4.741

Quintana, D. S., Alvares, G. A., \& Heathers, J. A. (2016). Guidelines for reporting articles on psychiatry and heart rate variability (GRAPH): recommendations to advance research communication. Translational Psychiatry, 6:e803. doi:10.1038/tp.2016.73

Quintana, D. S, Guastella, A. J., Outhred, T., Hickie, I. B., \& Kemp, A. H. (2012). Heart rate variability is associated with emotion recognition: Direct evidence for a relationship between the autonomic nervous system and social cognition. International Journal of Psychophysiology, 86. 168-172. doi:10.1016/j.ijpsycho.2012.08.012

Quintana, D. S., \& Heathers, J. A. (2014). Considerations in the assessment of heart rate variability in biobehavioral research. Frontiers in Psychology, 5, 805. doi:10.3389/fpsyg.2014.00805

Rokeach, M. (1954). The nature and meaning of dogmatism. Psychological Review, 61(3), 194-204. doi:10.1037/h0060752

Rottenberg, J., Salomon, K., Gross, J. J., \& Gotlib, I. H. (2005). Vagal withdrawal to a sad film predicts subsequent recovery from depression. Psychophysiology, 42, 277-281. doi:10.1111/j.1469-8986.2005.00289.x 
Ruiz-Padial, E., Sollers, J. J., Vila, J., \& Thayer, J. F. (2003). The rhythm of the heart in the blink of an eye: Emotion-modulated startle magnitude covaries with heart rate variability. Psychophysiology, 40(2), 306-313. doi:10.1111/1469-8986.00032

Salomon, K., Burgess, K. D., \& Bosson, J. K. (2015). Flash fire and slow burn: Women's cardiovascular reactivity and recovery following hostile and benevolent sexism. Journal of Experimental Psychology: General, 144(2), 469-479. doi:10.1037/xge0000061

Scarpa, A., Haden, S. C., \& Tanaka, A. (2010). Being hot-tempered: autonomic, emotional, and behavioral distinctions between childhood reactive and proactive aggression. Biological Psychology, 84(3), 488-496. doi:10.1016/j.biopsycho.2009.11.006

Sgro, N., \& Guimond, S. (2004). Dogmatisme et idéologie politique : Validation française d'une mesure du rejet dogmatique d'autrui (DRS). Cahiers Internationaux de Psychologie Sociale, 62, 77-88.

Sidanius, J., \& Pratto, F. (1999). Social dominance: an intergroup theory of social hierarchy and oppression. New Work: Cambridge University Press.

Singh, J. P., Larson, M. G., O'Donnell, C. J., Tsuji, H., Evans, J. C., \& Levy, D. (1999). Heritability of heart rate variability: the Framingham Heart Study. Circulation, 99(17), 2251-2254. doi:10.1161/01.cir.99.17.2251

Stellar, J. E., Cohen, A., Oveis, C. \& Keltner, D. (2015). Affective and physiological responses to the suffering of others: Compassion and vagal activity. Journal of Personality and Social Psychology, 108(4), 572-585. doi:10.1037/pspi0000010

Suchday, S., Carter, M. M., Ewart, C. K., Larkin, K. T., \& Desiderato, O. (2004). Anger cognitions and cardiovascular recovery following provocation. Journal of Behavioral Medicine, 27(4), 319-341. doi:10.1023/B:JOBM.0000042408.80551.e1

Task Force of the European Society of Cardiology and the North American Society of Pacing and Electrophysiology (1996). Heart rate variability. Standards of measurement, 
physiological interpretation and clinical use. Circulation, 93(5), 1043-1065. Retrieved from http://www.escardio.org/static_file/Escardio/Guidelines/ScientificStatements/guidelines-Heart-Rate-Variability-FT-1996.pdf

Thayer, J. F., Ahs F., Fredrikson, M., Sollers J. J., III, \& Wager, T. D. (2012). A meta-analysis of heart rate variability and neuroimaging studies: implications for heart rate variability as a marker of stress and health. Neuroscience and Biobehavioral Reviews, 36(2), 747756. doi:10.1016/j.neubiorev.2011.11.009

Thayer, J. F., Hansen, A. L., Saus-Rose, E., \& Johnsen, B. H. (2009). Heart rate variability, prefrontal neural function and cognitive performance: the neurovisceral integration perspective on self-regulation, adaptation, and health. Annals of Behavioral Medecine, 37(2), 141-153. doi:10.1007/s12160-009-9101-z

Thayer, J. F., \& Lane, R. D. (2000). A model of neurovisceral integration in emotion regulation and dysregulation. Journal of Affective Disorders, 61(3), 201-216. doi:10.1016/S0165-0327(00)00338-4

Thayer, J. F., \& Lane, R. D. (2007). The role of vagal function in the risk for cardiovascular disease and mortality. Biological Psychology, 74(2), 224-242. doi:10.1016/j.biopsycho.2005.11.013

Thomsen, L., Green, E. G. T., \& Sidanius, J. (2008). We will hunt them down: How social dominance orientation and right-wing authoritarianism fuel ethnic persecution of immigrants in fundamentally different ways. Journal of Experimental Social Psychology, 44(6), 1455-1464. doi:10.1016/j.jesp.2008.06.011

Tran, T. B, Siemer, M., \& Joormann, J. (2011). Implicit interpretation biases affect emotional vulnerability: A training study. Cognition and Emotion, 25(3), 546-558. doi:10.1080/02699931.2010.532393 
Tritt, S. M., Peterson, J. B., \& Inzlicht, M. (2013). Preliminary support for an arousal model of political conservatism. Plos One, 8(12), e83333. doi:10.1371/journal.pone.0083333

van der Schalk, J., Hawk, S. T., Fischer, A. H., \& Doosje, B. (2011). Moving faces, looking places: validation of the Amsterdam Dynamic Facial Expression Set (ADFES). Emotion, 11(4), 907-920. doi:10.1037/a0023853.

van Randenborgh, A., Hüffmeier, J., LeMoult, J., \& Joormann, J. (2010). Letting go of unmet goals: Does self-focused rumination impair goal disengagement? Motivation and Emotion, 34(4), 325-332. doi:10.1007/s11031-010-9190-9

Vella, E. J., \& Friedman, B. H. (2009). Hostility and anger in: cardiovascular reactivity and recovery to mental arithmetic stress. International Journal of Psychophysiology, 72(3), 253-259. doi: 10.1016/j.ijpsycho.2009.01.003

Vigil, J. M. (2010). Political leanings vary with facial expression processing and psychosocial. Group Processes and Intergroup Relations, 13(5), 547-558. doi:10.1177/1368430209356930gpir.sagepub.com

Weissflog, M. J., van Noordt, S. J. R., Choma, B. L., Dywan, J., \& Segalowitz, S. J. (2010). Sociopolitical ideology and electrocortical responses. Psychophysiology, 47(Sup), S24. Wendt, J., Neubert, J., Koenig, J., Thayer, J. F., \& Hamm, A. O. (2015). Resting heart rate variability is associated with inhibition of conditioned fear. Psychophysiology, 52(9), 1161-1166. doi:10.1111/psyp. 12456

Williams, D. P., Cash, C., Rankin, C., Bernardi, A., Koenig, J., \& Thayer, J. F. (2015). Resting heart rate variability predicts self-reported difficulties in emotion regulation: A focus on different facets of emotion regulation. Frontiers in Psychology, 6, Article 261. doi:10.3389/fpsyg.2015.00261

Wilson, G. D. (1973). The psychology of conservatism. London: Academic Press. 